\title{
Cleaning the pipes before changing the furnace: Endoscopic patient optimization before major therapeutic intervention in lung cancer
}

\author{
Moishe Liberman, MD, PhD
}

\footnotetext{
From the Division of Thoracic Surgery, University of Montréal; and CETOC-CHUM Endoscopic Tracheobronchial and Oesophageal Center, Montréal, Québec, Canada.

Disclosures: Author has nothing to disclose with regard to commercial support.

Received for publication May 14, 2016; accepted for publication May 26, 2016; available ahead of print June 22, 2016.

Address for reprints: Moishe Liberman, MD, PhD, CETOC Division of Thoracic Surgery, Centre Hospitalier de l'Université de Montréal, 1560 rue Sherbrooke Est, 8e CD, Pavillon Lachapelle, bureau D-8051, Montréal, Québec, Canada H2L 4M1 (E-mail: moishe.liberman@umontreal.ca).

J Thorac Cardiovasc Surg 2016;152:e69

$0022-5223 / \$ 36.00$

Copyright (C) 2016 by The American Association for Thoracic Surgery

http://dx.doi.org/10.1016/j.jtcvs.2016.05.038
}

Interventional bronchoscopic endoluminal airway treatment can allow for patient optimization before aggressive, potentially curable, treatment strategies in tumors causing airway obstruction with lung atelectasis (Figure 1). Patients often present with severe dyspnea and in a catabolic state as the result of lung atelectasis and postobstructive pneumonia and are unable to be properly worked-up for potentially curative intent treatment (surgery, definitive chemoradiotherapy) because of their respiratory and physical status. In certain cases with preserved lung parenchyma distal to airway obstruction, interventional bronchoscopy can rapidly restore airway patency to allow patient optimization and work-up for potentially curative therapy.

Airway restoration can be achieved with the use of a combination of techniques, including flexible and rigid bronchoscopy, laser therapy, electrocautery, argon beam, mechanical debridement, airway dilation, and airway stenting, depending on the anatomic circumstance. ${ }^{1-3}$ In patients who may be considered for definitive surgical resection of the primary tumor, stenting should either be avoided or extreme caution

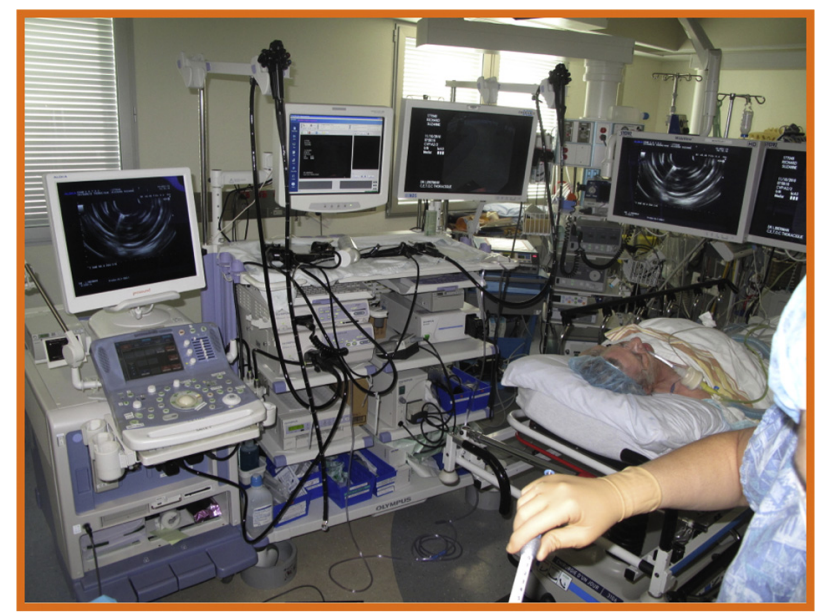

FIGURE 1. Thoracic interventional endo suite used for staging, optimization, treatment, and palliation.

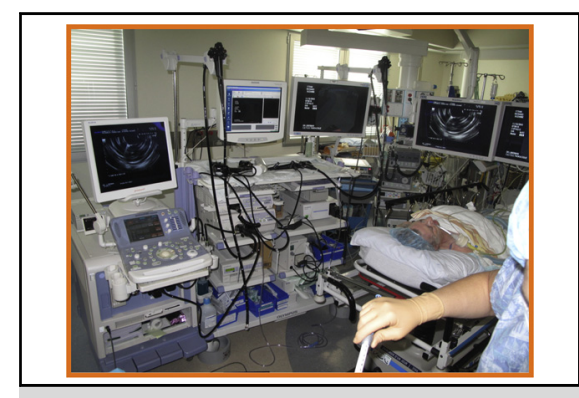

Thoracic interventional endo suite used for staging, optimization, treatment, and palliation.

\section{Central Message}

Interventional bronchoscopic treatment can allow for patient optimization before aggressive, potentially curable, treatment strategies in tumors causing airway obstruction with lung atelectasis.

See Article page e65.

should be used to assure not to damage normal proximal and distal airway at the sites of future tracheobronchial anastomoses. An advanced endoscopic skill set is required to endoscopically treat these complex patients.

In this edition of the Journal, Dr Wu and colleagues ${ }^{4}$ nicely describe a case of complete lung atelectasis in a decompensated patient. Using a custom-made metallic stent, they successfully were able to restore right lung airway patency with complete resolution of distal atelectasis. The patient was able to recover respiratory function, improve in clinical status, and undergo definitive treatment of nonsmall cell lung cancer. This report highlights the importance of interventional thoracic endoscopy in the overall treatment of advanced lung cancers involving the tracheobronchial tree. This article is a nice example of the broadening indications for endoscopy in patients, not only for palliation, but also in the overall care of potentially curable patients.

\section{References}

1. Liberman M. Bronchoscopic evaluation of the trachea and dilation of the trachea. Semin Thorac Cardiovasc Surg. 2009;21:255-62.

2. Ost DE, Ernst A, Grosu HB, Lei X, Diaz-Mendoza J, Slade M, et al. Therapeutic bronchoscopy for malignant central airway obstruction: success rates and impact on dyspnea and quality of life. Chest. 2015;147:1282-98.

3. Semaan R, Yarmus L. Rigid bronchoscopy and silicone stents in the management of central airway obstruction. J Thorac Dis. 2015;7(suppl 4):S352-62.

4. Wu G, Zongming L, Jiao D, Han X. Sequential interventional treatment of right-sided lung cancer with complete lung atelectasis: a case report. J Thorac Cardiovasc Surg. 2016;152:e65-7. 